\title{
A Study on the Transformation of Accounting Based on New Technologies: Evidence from Korea
}

\section{Sora Yoon}

School of Business, Ajou University, Suwon 16499, Korea; yoonsora@ajou.ac.kr; Tel.: +82-31-219-2729

Received: 9 September 2020; Accepted: 15 October 2020; Published: 19 October 2020

\begin{abstract}
This study identifies the new accounting technologies into Cloud, Artificial Intelligence, Big Data, and Blockchain, and introduces the case of Korean companies applying new technologies to their accounting process. The purpose of this study is to help understand accounting technologies and provide examples of the adoption of these technologies in actual practice. To achieve this aim of the study, a systematic review of the literature of the major academic publications and professional reports and websites was used as a research methodology. In order to select the cases, it performed the analytical process of reviewing Korean major business and economic newspaper articles. This study provides evidence from Korea to companies contemplating the transformation of their accounting process using technology. Such companies can consider the cases presented in this study as a benchmark. It also offers guidance for the application of technologies to accounting practices for businesses and related researchers. The technology transformation is expected to be accelerated, especially after COVID-19. Therefore, it is necessary to understand and explore ways to effectively apply them. Further, while new technologies offer many opportunities, associated risks and threats should be addressed.
\end{abstract}

Keywords: accounting technology; artificial intelligence; big data; blockchain; cloud; machine learning; robotic process automation; technology transformation

\section{Introduction}

In recent years, the technological advance of Artificial Intelligence (AI), Big Data, and Cloud has become the core of the era of Industry 4.0 worldwide. This new trend has reduced the need for employment in specific areas, and the possibility of changing industrial structures has been greatly addressed (Frey and Osborne, 2017) [1]. According to PwC's Global Industry 4.0 Survey (2016) [2], the efforts of responding to Industry 4.0 will have significant impacts in all areas of industry, such as cost reduction, efficiency improvement, and profit expansion. For example, AI has functions of Robotic Process Automation (RPA) and Deep Learning (DL), and this will enable computer processing capability to be significantly improved. A process that required a considerable amount of time in the past can be done instantly now. These new technologies have already been introduced in various areas. Piccarozzi et al. (2018) [3] reviewed the topics of Industry 4.0 in management literature and stated that the Fourth Industrial Revolution leads to adopting information technologies in manufacturing and services in a private environment. Milian et al. (2019) [4] address financial technologies such as fintech, and Arundel et al. (2019) [5] discuss technological innovation adopted in the public sector. Rikhardsson and Yigitbasioglu (2018) [6] address business intelligence and big data analytics in management accounting areas as well. The new technologies have been adopted not only in corporations and in private sectors including autonomous driving, business support, and marketing, but also in national institutions and public sectors such as education, finance, fintech, medical care, environment, security, the military, and so on. 
The emergence of new technologies has dramatically transformed the entire process of accounting, as well. In the past, most accounting processes were performed manually or with the limited uses of computer for just book-keeping. However, as Information and Communication Technologies (ICT) have developed, technologies such as AI, Cloud, and Big Data are widely and actively used in accounting processes. This is referred to as the digital "transformation" of accounting in this study.

These new technologies not only enable large volumes of data to be processed almost instantly, but they also help achieve increased transparency. These are employed at all stages beginning from the collection of accounting data to the final decision-making process.

Accounting data are collected and produced with the Cloud system. Big Data analytics and Artificial Intelligence (AI), including Robotic Process Automation (RPA) and Machine Learning (ML) can be used to generate more meaningful and relevant accounting information for better decision-making. Using Blockchain technology enhances the quality of accounting information and ensures transparency and reliability. The purpose of this study is to present these cases of Korean companies applying new technologies to their accounting process and provide direction to companies considering such transformation. This study aims at providing evidence from Korea to companies contemplating the transformation of their accounting process using technology. Such companies can consider the cases presented in this study as a benchmark, seeking guidance in them. Many studies described new technologies. However, ones providing specific cases of adoption are rare. This study helps understand how these new technologies can be applied to organizations by discussing real-world examples.

The utilization of new technologies in the accounting areas mentioned above is now taking place worldwide, and Korea is not an exception. Using the Cloud system, small and mid-sized fintech start-ups are running with an inter-business e-commerce fintech platform. They are operating more integrated accounting systems using various types of Big Data, including videos, images, and even drones. Companies become able to manage their inventory in a more effective way by adopting Post of Sales (POS) data. On the one hand, companies incorporate with local government and establish a more efficient taxation system. On the other hand, firms can secure transparency by applying blockchain technology to the Trading System in Korea. Table 1 compares the new accounting technologies adopted in Korea and worldwide by each area of accounting. It shows the literatures addressing these technologies as well.

Table 1. Accounting technology adopted in Korea and other countries.

\begin{tabular}{|c|c|c|c|c|}
\hline \multirow{2}{*}{ Areas } & \multicolumn{2}{|l|}{ Korea } & \multicolumn{2}{|c|}{ Other Countries } \\
\hline & Technology & Literatures & Technology & Literatures \\
\hline \multirow[t]{6}{*}{$\begin{array}{l}\text { Financial } \\
\text { accounting }\end{array}$} & $\begin{array}{l}\text { Inter-business e-commerce } \\
\text { fintech platform }\end{array}$ & Kim (2020) & $\begin{array}{l}\text { Cloud service such as } \\
\text { automatic } \\
\text { accounting system }\end{array}$ & ACCA/IMA (2013) \\
\hline & Automatic accounting system & Lee H (2020) & & \\
\hline & Inventory management using & Lee H $(2020)$ & & \\
\hline & POS data & eBlueChannel (2020) & & \\
\hline & XBRL & & XBRL & Deloitte (2017) \\
\hline & Big Data-based accounting records & Kim A (2018) & $\begin{array}{l}\text { Big Data-based } \\
\text { accounting records }\end{array}$ & Warren et al. (2015) \\
\hline \multirow[t]{3}{*}{$\begin{array}{l}\text { Management } \\
\text { accounting }\end{array}$} & AI-based Balanced ScoreCard & Yook (2019) & $\begin{array}{l}\text { Blockchain-based } \\
\text { Balanced ScoreCard }\end{array}$ & Warren et al. (2015) \\
\hline & Performance prediction & & & \\
\hline & Cost determination & & Cost determination & $\begin{array}{l}\text { Breiman (2001) } \\
\text { Cutler et al. (2012) }\end{array}$ \\
\hline \multirow[t]{2}{*}{ Audit } & AI-based fraud detection system & Cho et al. (2018) & $\begin{array}{l}\text { Robotic process } \\
\text { automation }\end{array}$ & Schatsky et al. (2016) \\
\hline & & & Continuous audit & Vasarhelyi et al. (2010) \\
\hline \multirow[t]{2}{*}{ Taxation } & Autonomous taxation system & Cho et al. (2018) & RPA Tax system & $\begin{array}{l}\text { PwC (2017) } \\
\text { Kira (2018) }\end{array}$ \\
\hline & $\begin{array}{l}\text { Big Data-based tax payment and } \\
\text { tax investigation service }\end{array}$ & $\begin{array}{l}\text { Song (2017) } \\
\text { Korean National Tax } \\
\text { Service (2016) }\end{array}$ & & \\
\hline Others & Blockchain-based Trade platform & $\begin{array}{l}\text { Korean Customs } \\
\text { Service (2017) }\end{array}$ & Smart Contracts & O’Neill (2016) \\
\hline
\end{tabular}


In order to achieve the aim of this study, a systematic review of the literatures discussing the adoption of new technologies in accounting areas is used as methodology. Therefore, the next section briefly discusses the background of accounting technologies and prior studies. Section 3 presents the research methodology of a systematic review of the literatures. Section 4 covers Korean cases that have adopted Cloud, AI, Big Data, and Blockchain. Section 5 integrates the findings of this study and provides a framework on the impact of technologies on accounting. The final section includes the conclusion, limitations of this study, and closing remarks.

\section{Backgrounds of Accounting Technologies}

Many research papers and reports discussed accounting technologies, defining them in various ways. The Association of Charted Certified Accountants (ACCA) and the Institute of Management Accounts (IMA) reported on the future of accounting titled "Digital Darwinism" [7]. This report discussed 10 technology trends with the potential of significantly reshaping the business and professional environment, namely, Mobile, Big Data, AI and robotics, Cybersecurity, Educational, Cloud, Payment systems, Virtual and augmented reality, Digital service delivery, and Social (ACCA/IMA, 2013; 10) [7]. On the one hand, the Institute of Chartered Accountants in England and Wales (ICAEW) identified AI, Big Data, Blockchain, and Cybersecurity as technologies transforming the accounting industry (IFAC, 2019) [8]. Forbes (2018) [9] reported that harnessing the power of the Cloud, accelerating automation, breakthroughs via Blockchain were the future accounting trends. Accounting technology can be identified in various ways, and these technologies are not limited to accounting. In fact, they are used actively in other areas, such as autonomous vehicles, financial engineering, and so on.

There are many articles presenting the advantages of Cloud technology in accounting. According to Ionescu et al. (2013) [10], simplification of accounting documents and migration of certain accounting operations to cloud-based electronic platforms have significantly changed accounting information system. Ionescu et al. (2013) [10] verified the cost saving generated by the utilization of a cloud computing-based application and stated that this is an important and relevant criterion when selecting the internet-based accounting solution. Christauskas and Miseviciene (2012) [11] believed that digital technologies including Cloud potentially increase the quality of the business-related decision process. In addition, Phillips (2012) [12] mentioned that clients and accountants could always be communicated with through the Cloud. The security of data can be ensured by the cloud provider and the risk of unsynchronized data can be eliminated.

The Financial Stability Board reported AI technology would enable accountants to focus on more valuable tasks such as decision-making, problem solving, advising, strategy development, and leadership (FSB, 2017) [13]. Deloitte (2017) [14] presented that RPA accelerates greater automation of process and $\mathrm{AI}$ improves productivity in public sectors. Accuracy and efficiency can be increased and operating costs and time can be reduced in performing accounting tasks and process by AI technology. AI can provide higher quality information by machine or deep learning, and contribute to generate more transparent accounting information (Ahn and Jung 2018; Bauguess 2017; Cho et al. 2018; O’Neill 2016; PwC 2017) [15-17].

Big Data present many important implications for accounting. Warren et al. (2015) [18] stated that video and image data, audio data, and textual data are different types of Big Data as a supplement to existing accounting records, and this information made available through Big Data can provide improved accounting practices. In an increasingly complex and high-volume data environment, the use of technology and Big Data analytics offers greater opportunities in all accounting areas. For example, auditors can obtain a more effective and robust understanding of the entity and its environment, and enhance the quality of the auditor's risk assessment and response (IAASB, 2016: 7) [19].

Prior studies stated that Blockchain is a technology with a direct impact on the accounting profession. Blockchain is a data decentralization-based technique (Raval 2016) [20]. Various data are saved on a list of records called blocks and these blocks are linked like chains using cryptography. It is an open, distributed ledger that can record transactions between two parties efficiently and in a verifiable 
and permanent way (Iansiti and Lakhani 2017) [21]. Once recorded, the data in any given block cannot be altered retroactively without alteration of all subsequent blocks, which requires consensus of the network majority (Raval 2016) [20]. Therefore, modification, alternation, and manipulation of data become improbable (if not impossible). PwC (2016) [22] presented that Blockchain is considered as the next generation of business-processing software where transactions are shared among customers, competitors, and suppliers. Particularly, Blockchain with functions that enable data integrity, rapid processing and sharing, and programmatic and automatic control processing will significantly contribute to developing new accounting systems.

Given these studies mentioned above, this study summarizes the new technologies ushering significant changes in accounting into Cloud, AI including RPA and ML, Big Data, and Blockchain. In the following section, I present the research methodology and explain the selection backgrounds and how these technologies and cases are adopted for this study.

\section{Research Methodology}

For this study, I followed the guidelines for a systematic literature review described by Schmitz and Leoni (2019) [23]. Using their two-phase approach, academic research, professional reports, and websites were reviewed. Then, a thematic analysis to identify the main themes and topics was performed.

First of all, this study performed a systematic review of academic publications and literature on the new technologies in accounting areas. The review period ranges from 2000 to 2019. I collected the relevant publications by searching on Google Scholar with the keywords of "new technology," "Industry 4.0," and "digital transformation". From this initial process, only peer-reviewed academic journal articles and book chapters written in English and Korean were considered. Following Cockcroft and Russell's (2018) [24] approach, I conducted a comprehensive screen of search results and excluded the publications whose content was not related to technology in the accounting domain. The result can be summarized in 22 academic publications that explicitly address accounting technologies and Table 2 shows the list of selected academic sources.

Table 2. Themes of accounting technology appeared in previous academic literature.

\begin{tabular}{|c|c|c|c|c|c|}
\hline No. & Author(s) and Year & Cloud & AI & Big Data & Blockchain \\
\hline 1 & Bauguess (2017) & & $\checkmark$ & $\checkmark$ & \\
\hline 2 & Breiman (2001) & & $\checkmark$ & & \\
\hline 3 & Cho et al. (2018) & & $\checkmark$ & & \\
\hline 4 & $\begin{array}{l}\text { Christauskas and } \\
\text { Misevicience (2012) }\end{array}$ & $\checkmark$ & & $\checkmark$ & \\
\hline 5 & Cutler et al. (2012) & & $\checkmark$ & & \\
\hline 6 & Feng $(2015)$ & $\checkmark$ & & $\checkmark$ & \\
\hline 7 & Fanning and Centers (2016) & & & & $\checkmark$ \\
\hline 8 & Hoogduin et al. (2014) & & $\checkmark$ & $\checkmark$ & \\
\hline 9 & Hughes et al. (2019) & & & & $\checkmark$ \\
\hline 10 & Ionescu et al. (2013) & $\checkmark$ & & & \\
\hline 11 & Kwon et al. (2014) & & & $\checkmark$ & \\
\hline 12 & Lee et al. (2015) & & $\checkmark$ & $\checkmark$ & \\
\hline 13 & Lee et al. (2019) & & & $\checkmark$ & $\checkmark$ \\
\hline 14 & O’Neill (2016) & & $\checkmark$ & & \\
\hline 15 & Phillips (2012) & $\checkmark$ & & & \\
\hline 16 & Schatsky et al. (2016) & & $\checkmark$ & & \\
\hline 17 & Seo and Kim (2016) & $\checkmark$ & & $\checkmark$ & \\
\hline 18 & Schmitz and Leoni (2019) & & & & $\checkmark$ \\
\hline 19 & Shin (2017) & & $\checkmark$ & & \\
\hline 20 & Vasarhelyi et al. (2010) & & $\checkmark$ & $\checkmark$ & \\
\hline 21 & Warren et al. (2015) & & & $\checkmark$ & \\
\hline 22 & Yook (2019) & $\checkmark$ & & & $\checkmark$ \\
\hline
\end{tabular}


In order to provide a more comprehensive perspective of the current development of practical applications of new technologies in the accounting industry, I further searched for professional reports and websites of the major professional accounting firms and associations worldwide. I defined the main professional accounting association as American Institute of Certified Public Accountants (AICPA), Association of Chartered Certified Accountants (ACCA), Institute of Chartered Accountants in England and Wales (ICAEW), Financial Stability Board (FSB), International Auditing and Assurance Standards Board (IAASB), International Federation of Accountants (IFAC), and the Big 4 audit firms including PwC, Deloitte, KPMG, and EY. I retrieved all relevant online sources from the websites of AICPA, ACCA, ICAEW, FSB, IAASB, IFAC, PwC, Deloitte, KPMG, and EY. Similar to the academic literature search, online sources that mentioned "new technology", "Industry 4.0", and "digital transformation" in accounting and auditing areas were selected. This web-based analysis resulted in a total of 10 publicly available sources in websites and reports, and Table 3 summarizes the results. This analytical process resulted in a list of four key technologies that can bring significant impact in accounting areas. The key topics are (1) Cloud, (2) AI, (3) Big Data, and (4) Blockchain.

Table 3. Themes of accounting technology appeared in professional reports and websites.

\begin{tabular}{cccccc}
\hline No. & Author(s) and Year & Cloud & AI & Big Data & Blockchain \\
\hline 1 & ACCA/IMA (2013) & $\checkmark$ & $\checkmark$ & $\checkmark$ & $\checkmark$ \\
2 & Deloitte (2017a) & & $\checkmark$ & & \\
3 & Deloitte (2017b) & & $\checkmark$ & & \\
4 & FSB (2017) & & $\checkmark$ & $\checkmark$ & \\
5 & IAASB (2016) & & & $\checkmark$ & \\
6 & IFAC (2019) & $\checkmark$ & $\checkmark$ & $\checkmark$ & $\checkmark$ \\
7 & PwC (2015) & $\checkmark$ & & $\checkmark$ & $\checkmark$ \\
8 & PwC (2016a) & & & & $\checkmark$ \\
9 & PwC (2016b) & $\checkmark$ & $\checkmark$ & $\checkmark$ & $\checkmark$ \\
10 & PwC (2017) & & $\checkmark$ & & \\
\hline
\end{tabular}

Besides Schmitz and Leoni's (2019) [23] two-phase analysis, this study performed the additional step analyzing Korean major newspaper articles to select cases adopting new technologies in the Korean market. I first searched the articles reporting new technologies in the financial or accounting sectors in 5 major Korean business and economic newspapers. Table 4 presents the cases reported, related topics, and the number of reports in the newspapers from the periods of August 2017 to August 2020.

Table 4. Korean cases and topics reported on newspapers.

\begin{tabular}{ccccc}
\hline Sector & Industry & Case & Topic & No. of Reports \\
\hline \multirow{2}{*}{ Private } & Financial & Bizplay & Cloud & 13 \\
& & WebCash & Cloud & 16 \\
\cline { 2 - 5 } & Managerial & AGREEMENT & AI & 5 \\
& & EasyKost & AI & 6 \\
& eBlueChannel & Cloud & 12 \\
\hline \multirow{2}{*}{ Public } & Tax & Orion & Cloud & 14 \\
& & Korean National Tax Service & Big Data & 8 \\
& & Korea Trade Network & Blockchain & 7 \\
& & (KTN)-uTradeHub system & Big Data & 9 \\
\hline
\end{tabular}

Based on the systematic literature review performed above, in the following Section 4, this study explains each of these four technologies selected focusing on presenting cases wherein these technologies were adopted in the Korean market. Although each technology is described separately for convenience, 
these technologies are intertwined with, and difficult to clearly separate from, each other. For example, the key driver of the development of AI is Big Data (Cho et al., 2018) [17], and combining Cloud computing with Big Data provides countless opportunities and benefits.

\section{Accounting Technologies Adopted in Korea}

\subsection{Cloud-Based Accounting}

Cloud is an internet-based technology resource, offering software applications, computing power, and data storage provided remotely as a service (ACCA/IMA, 2013: 10) [7]. Cloud accounting is an online accounting information system based on cloud computing, and customers use computers or other devices to achieve accounting and financial analysis functions (Feng, 2015: 207) [25].

The major objective of an accounting information system is collection and booking of data and information related to events with an economic impact on the organization, as well as the management, processing, and disclosure of information to internal and external users (Christauskas and Miseviciene, 2012) [11]. Therefore, the accounting system plays a key role in providing financial information used in the decision-making process (Christauskas and Miseviciene, 2012; Ionescu et al., 2013) [10,11]. Cloud is expected to play a key role in collecting and producing accounting data and information.

Figure 1 shows the communication models between accounting firms and clients presented by Phillips (2012) [12]. He stated that in the past, accountants communicated with their clients through FTP (file transfer protocol), RDP (remote desktop protocol), emails, or in-person meetings. The accounting process was inefficient, expensive, time consuming, and highly complex. However, recent accounting systems through Cloud simultaneously enable both clients and accountants to efficiently perform their jobs, ensure data security, improve data synchronization, and reduce the risk of unsynchronized data.
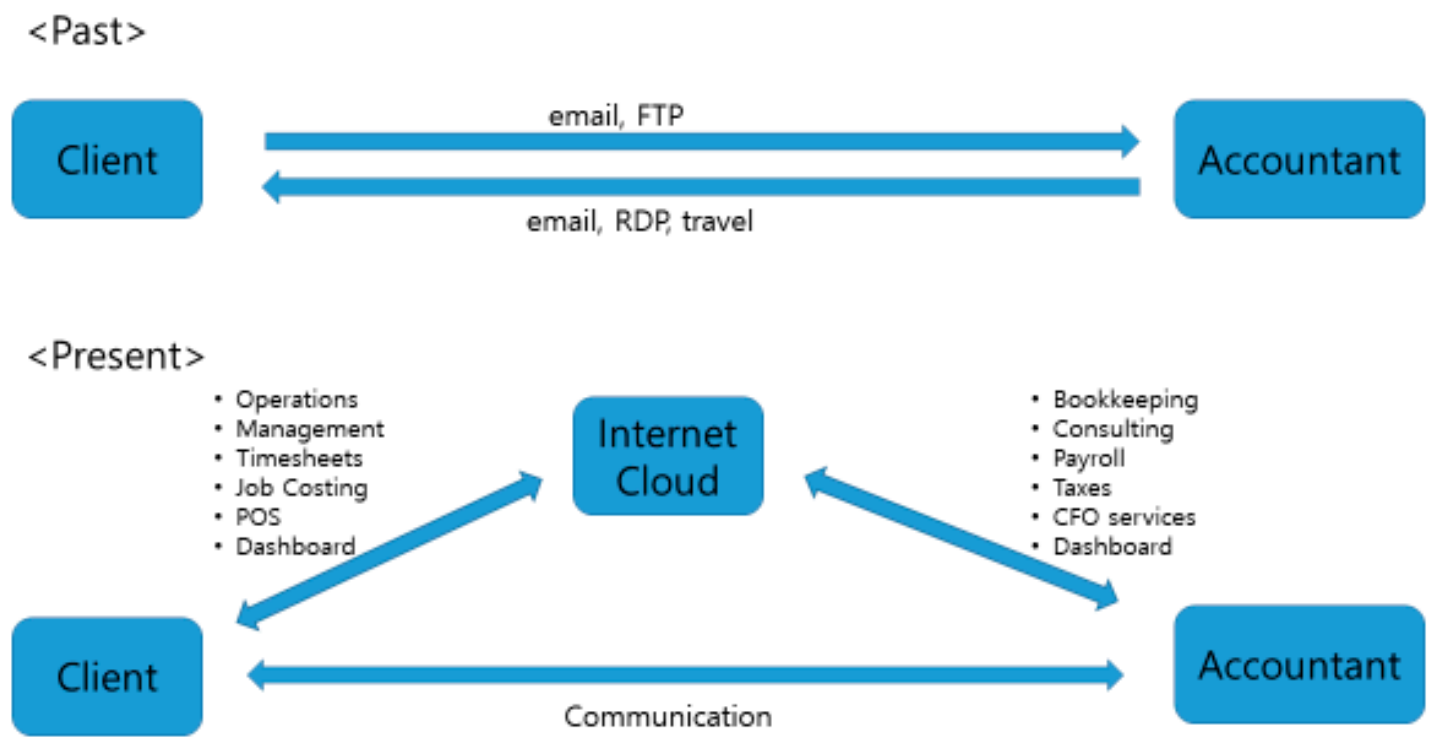

Figure 1. Past vs. Present Models of Communication. Source: Phillips, 2012:5, 6 [12].

One of the well-known cloud accounting systems is Enterprise Resource Planning (ERP). It is managed collectively, including all information from the company as well as supply chain management and customer order information. Accounting forms the core of the ERP system because accounting data are the key information managing all levels of business in an integrated manner. Therefore, they must be accurately aggregated.

In an interview with the Financial News Korea, Juergen Lindner, senior vice president of Oracle, mentioned the impending drastic changes due to the pandemic, and that Cloud could make prompt response to crises possible, strengthening the resilience of recovery. He also mentioned that the number of cases of adopting Cloud applications increased since COVID-19 (Kim A, 2020) [26]. 
Oracle ERP Cloud is widely used by large companies in the Korean market as it enables companies to handle large volumes of data on the cloud without their own data center. Oracle recently announced new Cloud Applications, including AI, digital assistant, and Analytics designed to experience benefits of these technologies, such as saving costs and improving productivity and management capabilities. Companies that adopt this system can make predictions by identifying and utilizing trends and patterns in financial and operational data, enabling timely decisions. The system automatically recognizes financial documents, such as PDFs, and minimizes manual invoicing operations, maintaining high accuracy even when the business environment changes frequently. This is also used in joint ventures where disputes among partners is frequent. Disputes can be resolved with the increased accounting visibility. Additionally, the cost of information processing technology (IT) has been reduced by more than $60 \%$ (Kim A, 2020) [26].

While Oracle provides Cloud services mainly to large-scale companies, WebCash is a Korean fintech start-up which runs an inter-business e-commerce (B2B) fintech platform. WebCash offers a different platform by company size. It provides a simpler accounting program called "Gyeongninara" for sole or small business owners and a more integrated accounting system called "Branch" to mid-sized business owners. Particularly, Gyeongninara is quickly settling down in the market since it enables accounting, taxation, receipt management, payment, and remittance all at once. The Cloud server automatically records purchases and sales, and collects detailed transaction data by client so that outstanding or unpaid bills can be automatically managed. Meanwhile, client companies experience a report-related work reduction by $90 \%$ by automatically collecting receipts of corporate credit cards, managing corporate credit cards in an integrated manner, and providing real-time trial balance through mobile devices. Consequently, WebCash's operating income increased by 39\% compared to last year since COVID-19 (Kim G, 2020) [27].

WebCash provides cloud services based on Platform as a Service (PaaS) (Cloud Services fall into the following three categories: Software as a Service (SaaS), Infrastructure as a Service (IaaS), and Platform as a Service (PaaS). Any user of free email service and social networking tools has used SaaS, and stored some of their data in a "public cloud," which is where IT resources, such as software, computing power, data storage, and related services are stored on the third-party computers. Resources are managed and maintained to be made available "on demand" to any individual or organization. Some are made available free to the end user, and some must be paid for (so-called "freemium"). IaaS means that users access remote computers and use them for storing data and performing computer-based processes. PaaS implies online access to the software and hardware needed to design, develop, test, and deploy applications, applications-hosting, and various associated services (ACCA/IMA, 2013) [7]. Bizplay is another Korean firm that provides cloud-based Software as a Service (SaaS). Bizplay clients download the app and all members of the organization can access the system. This lets them handle all expenses of registered corporate cards, manage and process receipts, check the usage history in real time and the credit card limit. This eliminates tedious and unproductive repetitive tasks for the organization's financial accounting team. The Bizplay app automatically matches the usage records of each employee and generates quality reports with paperless receipts. Thus, the financial accounting staff can monitor the status of company expenses in real time. Additionally, since COVID-19 has rendered working from the office difficult, Bizplay permits employees to handle related expenses without having to go to the office by simply uploading business-related documents using a smartphone camera. Bizplay also offers customized services for the customers' convenience, such as providing the Pro program for companies that want to manage their budgets more thoroughly in conjunction with the Lite program for small businesses (Lee S, 2020) [28].

These cloud-based accounting innovations have brought changes not only to financial reporting, but also to the management accounting aspect related to inventory management. One of the leading bakery companies in Korea, Orion, reported a product return rate of $0.6 \%$ (The average return rate of bakery industry in Korea is usually $2-3 \%$ (Lee H, 2020) [29] in the first quarter of 2020. This was nearly $80 \%$ lower than the rate 4 years ago (Lee H, 2020) [29]. Orion's sales and operating income in the first 
quarter increased by $7 \%$ and $29 \%$, respectively, from the same period last year, and this result was derived from the use of cloud-based Post of Sales (POS) (The definition of Post of Sales (POS) is a retail store, a cashier at the store, or the location where the transaction occurred. More specifically, POS refers to the hardware and software used for checkouts (Sularto et al., 2015) [30] data. POS data refers to real-time recorded data about goods sold. Orion increased its sales through real-time identification of rapidly changing consumption trends. The return rate significantly declined because the inventory was reduced in the production plan by reflecting on the consumption data in real time. New products with poor consumer response were promptly halted to minimize the costs of return, while production of new products with good consumer response were increased for more sales opportunities. The use of POS data is not a new concept. However, it is not easy for manufacturers to collect and utilize retailers' point of sales information, although many companies rely mainly on information from market research institutes, already a month old. Of those that utilize POS data from limited distribution channels, Orion was able to utilize meaningful data through continuous improvement in the system since 2015 by establishing a web-like collection network for each distribution channel as well as large wholesaler, supermarket, and convenience stores (Lee H, 2020), Ref. [29].

eBlueChannel is another Korean company that utilizes cloud-based POS data for inventory management. It is a data-based integrated drug management solution that connects manufacturers, pharmacies, and wholesalers. In this medical care solution, pharmacies, hospitals, and pharmaceutical manufacturers are all connected. Hence, they can quickly identify drug and medicine inventory. It is a complete medical platform combining all three categories (SaaS, IaaS, and PaaS) of cloud services. eBlueChannel manages the entire process related to the drug with the QR code from manufacturers to the merchant pharmacy. Since all processes require QR code scanning, it can analyze systematic sales data, simplify payment process, automate an ordering system by predicting consumption, and realize zero of unused inventory as well. Traditional medication management programs are limited to specialized medication (ethical-the-counter: ETC) management, making it almost impossible to manage general medicines (over-the-counter: OTC). Due to pharmacists' heavy workload entailing pharmacy preparation, patient response, and payment, inventory management of medicines is difficult for them. There are also problems of being exposed to various social risks due to illegal drug manufacturing or distribution of expired medicines through mass purchase of OTC medicines. eBlueChannel provides both inventory management functions of ETC and OTC, allowing a comprehensive check of inventory status and inventory information, as well as the management of the exact effective date of the medication. It also maximizes management efficiency through a data analysis system that supports the entire sales, payment, ordering, and statistical analysis process. eBlueChannel is an example of upgrading the value of medical business by realizing an automated process using new technology (eBlueChannel, 2020) [31]. eBlueChannel's technology is very similar to the system built during the COVID-19 pandemic to find out the available stock of surgical masks in drug stores.

As mentioned above, cloud computing enables companies to handle large volumes of data without their own data center and to manage key information of business in more integrated manner. Recent accounting system through Cloud simultaneously enables both clients and accountants to efficiently perform their jobs, ensures data security, improves data synchronization, and reduces the risk of unsynchronized data. Cloud is expected to play a key role in collecting and producing accounting data and information. Cloud is not just a technology. It is a trend leading the digital transformation of accounting. Cloud computing combined with Big Data has brought numerous opportunities and benefits. Big Data is the critical driver of the development of AI. Digital transformation does not merely mean a simple adoption or acceptance of technologies. It rather refers to leading a larger or structural shift comingled with the new technologies.

\subsection{AI-Based Accounting Process}

Artificial Intelligence (AI) has functions, such as machine learning and deep learning, which allow users to process a massive amount of work in a very short time-period, using a significantly 
improved computer processing ability (Yook, 2019) [32]. AI has been introduced in various fields, including autonomous driving, medical care, business support, finance, education, marketing, environment, security, and military. Particularly in accounting, the analysis and utilization of accounting data is promoted, enabling quicker high-level analysis, and using the results, it can be linked to management strategies or various other initiatives. Detecting fraudulent transactions, suspecting irregularities or errors early on, and recognizing and improving them in advance before problems occur is made possible (Yook, 2019) [32].

South Korea is currently finding ways to actively introduce AI to prevent accounting fraud. In the conference of Research on the Future Accounting, Shin (2017) [33] presented several key issues in building fraudulent accounting detection systems. First, it is important to build fraudulent financial statements' database. Collection of financial fraud-related data is critical because they can be important sources of AI using machine learning. Standardizing and connecting with the data is also crucial. Therefore, establishing extensible business reporting language (XBRL) is essential. The second issue is the use of unstructured or semi-structured data. Most systems used structured (numeric) data, such as financial ratios. However, a knowledge acquisition approach using various sources of data, such as verbal data from news, social network service (SNS), and footnotes also should go together.

The amount and quality of data are very important to establish an automated accounting system applying machine learning and artificial intelligence techniques. Data related to accounting fraud are lacking so far, research results are unreliable, and data quality is not guaranteed. This limits the practical use of these technologies in financial accounting and audit. However, there are examples of the use of AI techniques in taxation and managerial accounting.

In February 2018, AGREEMENT, an accounting software supplier, announced a management accounting enhancement solution called "Attack Board." This is a system wherein all employees and managers can access and visualize key performance index (KPI) (This is a Korean performance evaluation system which is adopted from the concept of Balanced Scorecard (BSC).), setting up to achieve the business plan and goal. To develop this accounting solution, AGREEMENT established a service that performs revenue forecasting using AI based on a framework for a risk approach that aims at working properly, identifying hidden risks behind the business, and utilizing the aggregation or reports of collected data. Specifically, the company developed a service that uses AI to predict sales by visualizing various qualitative risks that can be related to sales risk as a score, linking evaluation of intangible assets or positive factors with statistical data. Using a risk approach, the system predicts future figures from historical data considered to impact or correlate with sales. "Attack Board" uses a variety of machine learning algorithms that can be handled by Python to make sales forecasts. To do this, multiple algorithms can be used as a combination while adjusting each parameter to produce more precise predictions, thereby clarifying the issues that need to be improved, contributing to achieving sales goals (Yook, 2019) [32]. Further, if the actual performance differs from the plan, through the variance analysis, appropriate resource reorganization or re-examination of the process is provided.

$\mathrm{AI}$ is also used to estimate target costs. Prediction or estimation is a process of filling in missing information and generating information that does not currently exist, based on the data currently possessed. Until now, the following three methods are commonly used to estimate product cost: an analog method for estimating the cost of a new product compared to similar products produced or purchased in the past, analytical methods for estimating optimized theoretical costs by modeling manufacturing processes, and parametric methods for estimating product and service costs through statistical modeling according to specific parameters called cost drivers using a similar product or service history. The last statistical method including regression analysis is particularly useful in the early stages of the life cycle, but it also has some limitations because it rarely takes into account qualitative parameters, does not efficiently manage missing data, and requires a complete data set. In comparison, AI provides directions for a new model of cost estimation. Recent advances in algorithms and machine learning have largely resolved the shortcomings of traditional parameter methods and improved performance and application. For example, one of the latest statistical methods, 
the Random Forests algorithm, formally proposed by Breiman (2001) [34] and Cutler et al. (2012) [35], is a nonparametric approach to perform learning. This is a technique that selects the elements used to create each decision tree as random, and it builds multiple decision trees for the same data to aggregate the results to enhance predictive performance (Yook, 2019; Breiman, 2001; Cutler et al., 2012) [32,34,35]. The representative software that utilizes this AI algorithm is "EasyKost." This helps determine the cost of new products or services in seconds by utilizing the massive amounts of data without the need for specialized knowledge of industrial technologies and process. Many Korean software companies are trying to establish such cost estimation program in the Korean market.

Taxation is another area where advantages of AI can be witnessed. Figure 2 shows the differences between manual process, Robotic Process Automation (RPA), and RPA with cognitive technology.

South Korean local governments understand these differences and apply AI for accounting of collected tax. For example, the "Standard for Execution of Local Government Expenditure" states that assets with a useful life of less than one year should account for general administration expense, while other asset purchases are not subject to accounting for general administration expense. It is important to accurately input the items out of the numerous items in the execution of the expenditure. However, since it is done manually, there is a high likelihood of an input error. To obtain high quality data, there is no other way than to collect information accurately at the beginning of the task (Bauguess, 2017) [16].

If cognitive technology is applied to automatically classify as appropriate accounting items for the corresponding content, it may increase the probability of matching. The use of cognitive technology can provide benefits of more accurate prediction, improved resource allocation, anomaly detection, and real-time tracking without manual recognition of patterns and missing on key patterns, thereby helping to make better decisions and increase effectiveness (Deloitte, 2017: 10) [36].

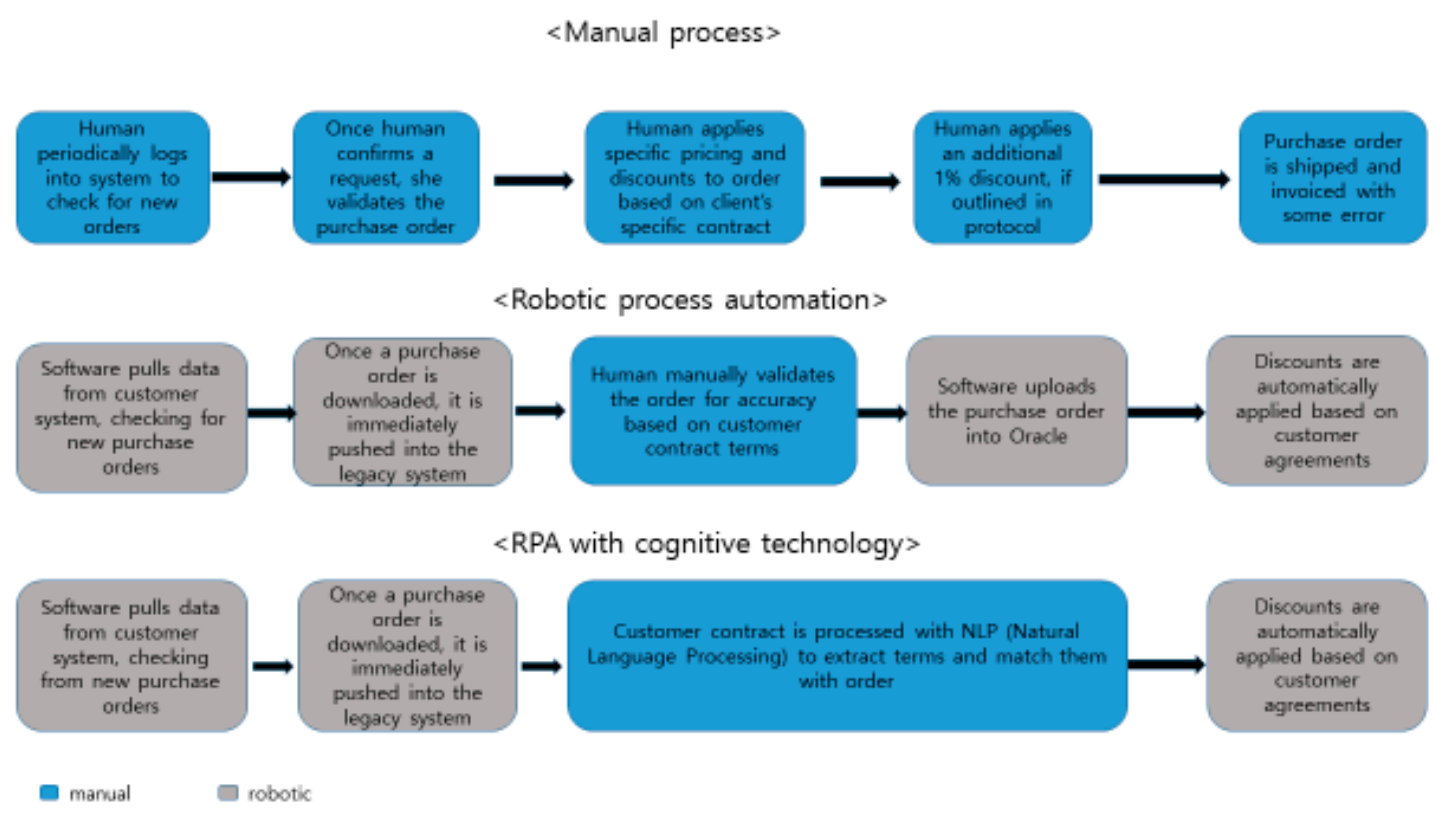

Figure 2. Manual vs. Robotic Process Automation (RPA) vs. RPA with Cognitive Technology. Source: Schatsky et al., 2016: 6, 7 [37].

Figure 3 is an example of how RPA applies to tax accounting and shows the potential for AI technology to be used in practice. For manual, repetitive, and time-consuming tasks, RPA can be adopted to enable the implementation of tax compliance and reporting-related technology solutions. Currently, there is a problem with local government accounting systems, which is an abnormal accounting process wherein only expenditure occurs without income because it is not accounted 
for when taxes are collected but accounted in a lump sum when collected taxes are expensed. Implementing accounting for tax collection with RPA can lead to a more proper accounting process.

$\mathrm{O}^{\prime} \mathrm{Neill}$ (2016) [38] also introduced intelligence technology that analyzes documents and contracts. He said that KPMG and IBM developed the cognitive computer, Watson, and Watson Analytics reads and summarizes thousands of pages of contract or agreement documents instantly. It shows virtual images, visualizes important parts, and distinguishes between what users should and should not be interested in. Deloitte partnered with Kira Systems to help review contracts and documents and provide evidence to support them. Kira (2018) [39] can visualize the terms of the contract in a picture that can be quickly identified, respond to law revisions, and review anti-bribery and force majeure cases. This system can also scan original documents and easily compare them with summary text. The Kira Review Platform API can understand all files in any format, and Kira API can be used to recall files and folders on the network or bring up future contracts with the repository. It can search a document with or without a clause and look for specific text within a clause. A built-in model of provisions, such as general terms of contract, compliance, and organization is implemented. Kira may also be taught to find legal provisions in a foreign language. Many modifications can be quickly presented in the contract. It is easy to identify revisions and changes across the entire set of contracts and analyze deviations through data visualization. The Korean government tried adopting AI technology like Kira for local government contract management. Adopting this has the potential of reducing serious disputes in government procurement contracts due to the failure of the public official in charge of checking the changes or errors caused by human beings. Since several kinds of extensive audits are carried out in the public sector, such as financial statement and performance audits (Cho et al., 2018: 274) [17], Korean local governments intend to actively use data analysis, including AI, RPA, and machine learning.
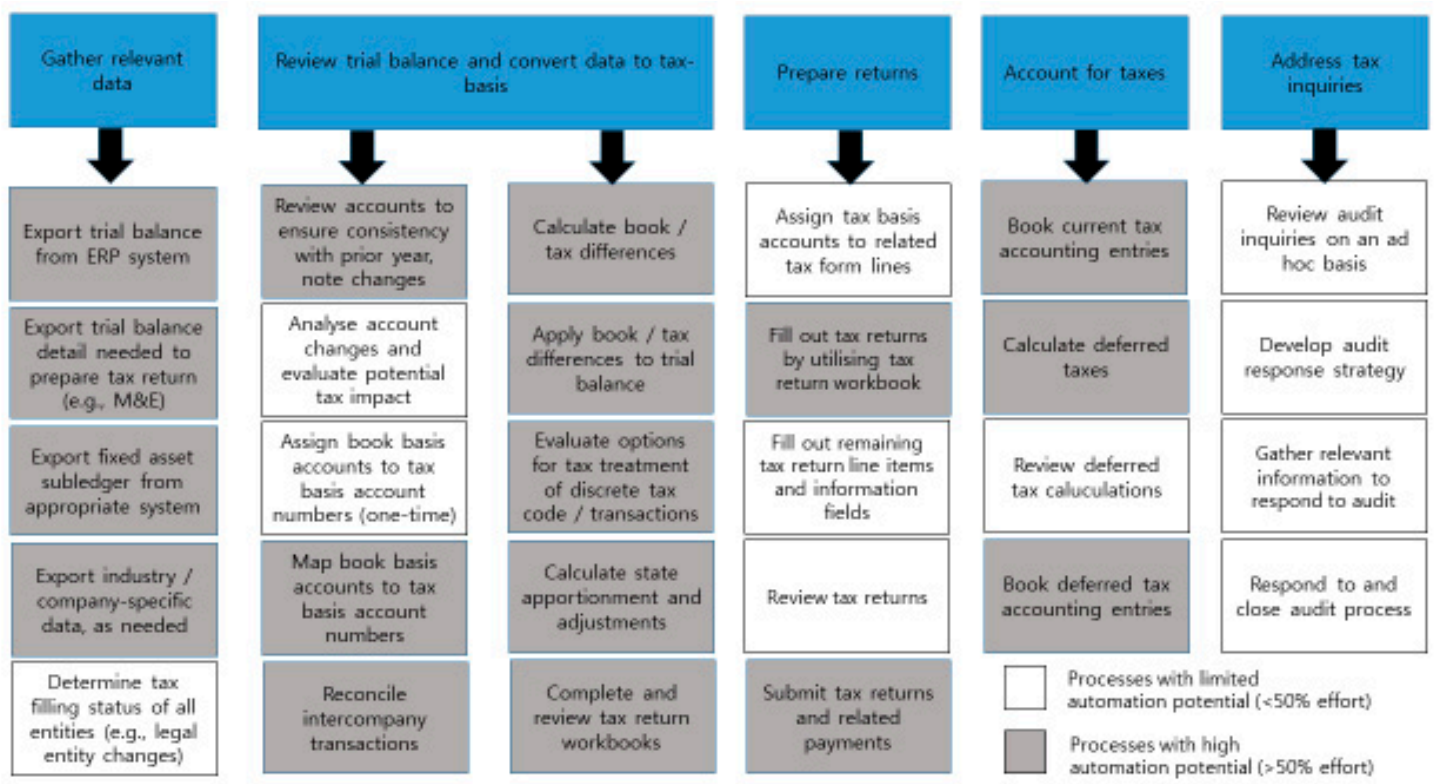

Figure 3. Examples of RPA Tax Opportunities. Source: PwC, 2017: 5 [40].

\subsection{Adoption of Big Data}

In addition to the above-mentioned use of AI technology, Korean National Tax Service also actively adopted Big Data technology. Korean National Tax Service formed a task force to prepare a roadmap for introducing Big Data, established a Big Data center in 2019, and utilized Big Data in all areas of tax administration, including tax payment services and tax investigations (Song, 2017) [41]. It established a new investigation division and enhanced its ability to cope with tax evasion by scientific investigation, such as the development of advanced forensics techniques and big data analysis (Korean National Tax Service, 2016) [42]. Examples of the use of Big Data by the National Tax Service include regular 
and non-regular earned income, past tax payment, credit card spending, credit card records, real estate status, car purchase records, overseas fund information sharing with more than 60 countries, online market access, online transaction, social media (Twitter, Facebook, Instagram, etc.), web search, emails, and so on. It reviews and collects these Big Data, and it analyzes and compares with previous tax payments.

Regarding the implementation of policies through the analysis of government 3.0 public data, Korean local governments conduct data analysis focusing on the economy, transportation, culture, communication, and safety (Lee et al., 2015: 10) [43]. The sources of Big Data for local administrative information, which are classified and opened by 244 local governments according to the contents of the service, include policy information, local government data (performance evaluation, audit, etc.), and local administrative statistical information (from 7 departments, including welfare and finance, 27 sectors, and 179 indicators) (Lee et al., 2015: 51) [43]. Korean local governments are indeed building a massive amount of Big Data.

Additionally, both public officials and accounting experts consider the national financial support program as an area very likely to utilize Big Data in financial accounting (Kwon et al., 2014: 274) [44]. The federal government-granted national financial aids are recorded in e-program, and all funds are managed in the e-program from the budget to expense stages, enabling public officials to always check the status of the national funds. Local governments can also automatically send the results to metropolitan and provincial government through e-program. Therefore, the government can effectively manage illegal execution of funds, such as embezzlement, bribery, poor execution, and fraudulent documents (Seo and Kim, 2016) [45].

Warren et al. (2015) [18] stated that video, image, audio, and textual data are all Big Data as a supplement to existing accounting records. These data are also used to manage public property in Korea. Suwon City, Gyeonggi Province introduced a new land investigation program using drones to secure accurate taxation data, shortening the investigation time and supplementing insufficient administrative power (Kim A, 2018) [46]. Up to this point, the land investigation method of imposing taxes was only a way for public officials to visit the site by comparing the land register with aerial photographs taken a year ago or by receiving reports. However, they now use drones to find lands that are being illegally and differently used from the original filing, and collect acquisition taxes on them (Kim I, 2018) [47].

Big Data affects the overall accounting areas and taxation. Conducting audits using Big Data is advantageous to auditors. According to the PwC (2015) [48] report, data analysts are changing the audit procedures with the new system, and auditors can use more information, including financial and non-financial data sets, and visualize the meaningful data. According to Vasarhelyi et al. (2010) [49], Big Data analytics can provide continuous audits and help mitigate audit risks. Hoogduin et al. (2014) [50] also state that the application of data scientists makes auditors perform more efficient audits, offering a way to provide new audit evidence not applied in the past. In financial accounting, Big Data will improve the quality and relevance of accounting information. Various accounting programs that can utilize Big Data are being actively developed in the Korean industry. For example, Smart A released by Douzone is an algorithm that applies Cloud and Big Data to allow users to proactively explore meaningful corporate information rather than just ex post facto exploration of financial information. Big Data is a new technology that can be used to provide relevant and meaningful information for better decision-making.

\subsection{Blockchain-Based Accounting}

Blockchain technology was first proposed by Satoshi Nakamoto (2008) [51] as a payment system for encrypted digital currencies. It was used as a security technology for transactions of the cryptocurrency Bitcoin developed in 2009. Consequently, there is a tendency to misinterpret Blockchain technology as a cryptocurrency, perceiving it with a negative image because of cryptocurrency's speculative nature. 
However, Blockchain is an information recording technology that uses encryption to prevent forgery or manipulation of information.

Schmitz and Leoni (2019) [23] describe Blockchain technology as an internet-based peer-to-peer network that uses cryptography. Peer-to-peer networks use a distributed application that allocates and shares tasks among peers participating in the network. Because of the distributed nature and its consensus mechanism, Blockchain technology provides a solution to control the ledger of recorded transactions. Every new record is added to existing blocks and these blocks are cryptographically linked. Due to this chain-shaped link, Blockchain can overcome the limits of double-entry bookkeeping such as the need for external assurance on companies' financial statements and the potential for fraud.

Although Blockchain technology offers these benefits, it has a number of limitations that need to be factored into any business case for adoption. Hughes et al. (2019) [52] identify the following limitations with Blockchain technology: lack of privacy, high costs, security model, flexibility limitations, latency, and governance. Besides, they mention that non-technical limitations including lack of acceptance from legal and regulatory authorities, and lack of user acceptance are also present.

However, recently, Blockchain has been adopted in various ways, transforming transactions throughout the industry. Fanning and Centers (2016) [53] claimed that Blockchain would significantly impact financial services because of its anti-corruption and information validity characteristics. It is expected to be widely used in medical and public sectors as well. Figure 4 shows the areas in which Blockchain can be applied.

\begin{tabular}{ll}
\hline \multicolumn{1}{c}{ Items } & \multicolumn{1}{c}{ Examples } \\
\hline Financial Instruments & $\begin{array}{l}\text { Currency, Private equities, Public equities, Bonds, Derivatives, } \\
\text { Voting rights, Trading records, Commodities, Spending records, } \\
\text { Mortgage / loan records, Crowd-funding }\end{array}$ \\
\hline Public Records & $\begin{array}{l}\text { Land titles, Vehicle registries, Business license, Business ownership } \\
\text { records, Regulatory records, Criminal records, Passports, Birth } \\
\text { certificates, Death certificates, Voter IDs, Building permits, Gun } \\
\text { permits, Forensic evidence, Court records }\end{array}$ \\
Private Records & $\begin{array}{l}\text { Contracts, Signatures, Wills, Trusts, Escrows, GPS trails } \\
\text { Other Semi-Public Records }\end{array}$ \\
$\begin{array}{l}\text { Degree, Certifications, Grades, HR records, Accounting records, } \\
\text { Business transaction records, Delivery records, Arbitration }\end{array}$ \\
Physical Asset Keys & $\begin{array}{l}\text { Home / apartment keys, Hotel room keys, Car keys, Safety deposit } \\
\text { box keys, Package delivery }\end{array}$ \\
Intangibles & $\begin{array}{l}\text { Coupons, Vouchers, Reservations, Movie ticket, Patents, Copyrights, } \\
\text { Trademarks, Software licenses, Music/movie/book licenses, Domain } \\
\text { names, Online identities }\end{array}$ \\
\hline Other & $\begin{array}{l}\text { Photos, audio, video, Date records, Sim cards, GPS network identity, } \\
\text { Spam control (micro-payments for posting) }\end{array}$ \\
\hline
\end{tabular}

Figure 4. Blockchain Application Areas. Source: The mega-master Blockchain lists (http://ledracapital. com/blog/2014/3/11/bitcoin-series-24-the-mega-master-blockchain-list).

Korea is also searching for ways to introduce Blockchain technology in line with the changing era. The Korean government announced Blockchain as the core technology of the fourth industrial revolution. It is making efforts to promote and educate about technology to preempt the future technology industry. On November 8 2018, a forum was held jointly by the Korea FinTech Association and the government. On this forum, the vice prime minister of Science and Information and Communication Technology (ICT) announced that 40 billion Korean won (US\$1 is approximately 1200 Korean won.) was set for the coming year's budget for Blockchain industry to be used for educating Blockchain specialists and expanding public demonstration projects, such as livestock product management and privately led pilot projects (Kim GY, 2018) [54].

Blockchain refers to a technology that distributes and stores all transactions and various data of all participants in a shared network. It is very secure, and it is difficult to manipulate transaction records because they are shared by all participants in the network. Blockchain verifies the validity 
of a transaction and secures reliability of the data (Lee et al., 2019) [55]. Due to its security and decentralization, it is applied to various industrial sectors, such as healthcare, finance, and supply chain management. It can be applied to all forms of record management and contracts in which security and auditability of transactions are important. In addition to financial sectors, such as securities trading, liquidation settlement, and remittance, investment, lending, and commodity exchange, Blockchain technology is also utilized in other areas, such as identification, notarial, ownership, electronic voting, transportation, and distribution (Lee et al., 2019) [55].

Blockchain is also used in identification. Because of Blockchain, the 21-year-old public identification system in Korea was abolished. The public certification system was first introduced 21 years ago in 1999, when internet use was still new, for self-authentication when government agencies issued civil documents or engaged in online financial transactions. However, issuance, done through financial institutions, is a complicated process. Certain web browsers must be connected, and it is difficult and inconvenient to integrate between computers and smartphones. It was abolished on 20 May 2020 as Blockchain technology is expected to be most commonly used technology for proving identity. As a result, the digital identification market (private authentication) that utilizes Blockchain entered an infinite competition in the Korean market (Hong, 2020) [56].

Industry and academia classify the level of Blockchain into three stages, depending on the scope of introduction and degree of activation of the technology: First-generation Blockchain technology (hereinafter referred to as Blockchain 1.0) is the generation that first started with Bitcoin's operating system. Blockchain 2.0 is the second generation technology that enables smart contracts. Finally, Blockchain 3.0 is the third generation, wherein smart contracts are used in various areas of society, such as public, political, and economic sectors. Korea has just moved beyond Blockchain 1.0 and is making efforts to promote technology and legislate for Blockchain 3.0 (Lee et al., 2019) [55].

Korea Trade Network (KTNET) recently implemented uTradeHub, an electronic trade infrastructure. It is a single-window system in which exporters and importers can handle all trade affairs without interruption by linking a number of related agencies, such as commercial banks, customs service, shipping/air companies, ranging from marketing, credit rating, to payment. It is established to simplify the trading procedures of trading companies and enhance the efficiency of their trade operations. (Source: https://www.utradehub.or.kr) uTradeHub currently provides a unified workplace for trading companies to conveniently and instantly process all trade business, from marketing, commerce, foreign currency exchange, customs clearance, logistics, to payment without any interruption. It is still in the early stages of implementation. Once in action, it will contribute towards trade automation innovation. It will also bring the benefits of reducing trading-related costs, increasing efficiency, and preventing fraudulent transactions if an uTradeHub is provided to prepare and exchange B2B information with foreign partners. KTNET is now working to establish a service that automatically submits necessary electronic documents to the National Tax Service (Korean Customs Service, 2017) [57].

The Korean government has been carrying out a large-scale project since 2018 to build a Blockchain platform that promotes business and technical verification with the participation of 48 companies related to exports and imports, aiming at strengthening the reliability and accuracy of documents and information. This service will provide advantages to all entities, including exporter, importer, shipping companies, insurance firm, logistics warehouses, and freight forwarders. The government is preparing to design and introduce a real-time autonomous accounting system called RAAS DApp to be applied on a trial basis to consignment processing trade first.

Consignment processing trade refers to the transaction of all or part of raw materials to be processed (including manufacturing, assembling, regenerating or remodeling) in a foreign country on the condition that they are processed, and then import or export processed goods (Article 1-0-2, 6 of the Foreign Trade Management Regulations) (Korean Customs Service, 2017) [57]. Figure 5 summarizes the flow of consignment processing trade. As shown, all transactions are identified and stored by each accounting subject using Blockchain technology. All transactions are recorded automatically with the unique number of the block in the ledger, and the transaction information and proof of 
accounting is stored together in the block. Therefore, it helps ensure transparency and reliability of accounting information.

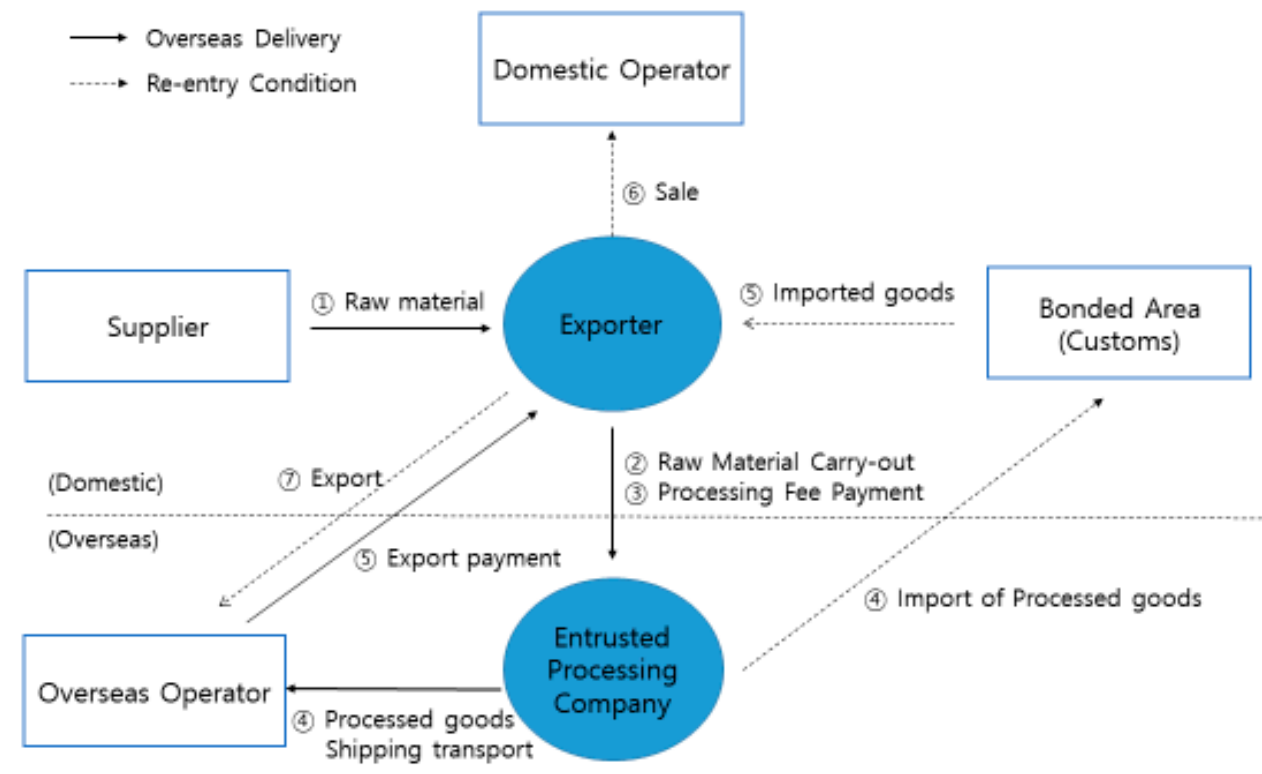

Figure 5. Trade Flowchart of Consignment Processing Trade. Source: Lee et al., 2019 [55].

\section{Discussion}

After analyzing the analytical process of systematic literature review, it was possible to summarize accounting technologies into four major topics. The main ideas of these accounting technologies already studied in the literature are presented in Table 5.

Table 5. Main ideas mentioned in prior literature.

\begin{tabular}{|c|c|c|}
\hline Theme & Study & Main Ideas \\
\hline Cloud & $\begin{array}{c}\text { ACCA/IMA (2013) } \\
\text { Feng (2015) } \\
\text { Christauskas and Misevicience (2012) } \\
\text { Ionescu et al. (2013) } \\
\text { Phillips (2012) }\end{array}$ & $\begin{array}{c}\text { Overall technology change in accounting } \\
\text { Accounting information model } \\
\text { Cloud accounting for small and mid-sized business } \\
\text { Comparison between traditional and cloud Accounting } \\
\text { Could computing adopted in accounting }\end{array}$ \\
\hline AI & $\begin{array}{c}\text { Yook (2019) } \\
\text { Shin (2017) } \\
\text { Breiman (2001) } \\
\text { Cutler et al. (2012) } \\
\text { Schatsky et al. (2019) } \\
\text { Bauguess (2017) } \\
\text { Deloitte (2017) } \\
\text { PwC (2016) } \\
\text { Kira (2018) } \\
\text { Cho et al. (2018) }\end{array}$ & $\begin{array}{c}\text { AI adopted in management accounting } \\
\text { Fraudulent accounting detection system } \\
\text { Machine learning } \\
\text { Machine learning } \\
\text { Robotic process automation } \\
\text { AI in assessing risks } \\
\text { Robotic process automation in the public sector } \\
\text { RPA in taxation system } \\
\text { AI for contract analysis } \\
\text { AI in audit }\end{array}$ \\
\hline Big Data & $\begin{array}{l}\text { Lee et al. (2015) } \\
\text { Kwon et al. (2014) } \\
\text { Seo and Kim (2016) } \\
\text { Warren et al. (2015) } \\
\text { PwC (2015) } \\
\text { Vasarhelyi et al. (2010) } \\
\text { Hoogduin et al. (2014) }\end{array}$ & $\begin{array}{c}\text { Data analysis management system for local government } \\
\text { Big Data in financial accounting information } \\
\text { Big Data as local government aids } \\
\text { Big Data technology change in accounting } \\
\text { Big Data change accounting education } \\
\text { Big Data utilization in audit, remote auditing } \\
\text { Integrating data for audit evidence }\end{array}$ \\
\hline Blockchain & $\begin{array}{l}\text { Fanning and Centers (2016) } \\
\text { Lee et al. (2019) } \\
\text { Korean Customs Service (2017) } \\
\text { Schmitz and Leoni (2019) } \\
\text { Hughes et al. (2019) }\end{array}$ & $\begin{array}{l}\text { The impact of blockchain on financial services } \\
\text { Accounting information system based on blockchain } \\
\text { Blockchain-based export customs service } \\
\text { Blockchain technology in accounting and auditing } \\
\text { Blockchain related academic research }\end{array}$ \\
\hline
\end{tabular}


Accounting is an integrated information providing system that collects company data, generates useful information, and makes it possible to manage them. Therefore, accounting information can be said to be a large set of Big Data. Utilizing the Big Data of a firm provides numerous advantages. As examined above, the Korean National Tax Service actively utilized Big Data technology. It established a new investigation division analyzing various forms of data, including past tax payment, credit card records, real estate status, car purchase records, overseas fund information, online market access, online transaction, social media, and so on. It enhanced its ability to detect tax evasion by scientific investigation, such as developing advanced forensics techniques and Big Data analysis (Korean National Tax Service, 2016) [42]. This is evidence that more efficient control systems can be developed using Big Data.

Additionally, this study presented the case of how to manage the federal government-granted national financial aids. They are recorded in the so-called e-program, and all funds are handled in the e-program from the budget to expense stages, enabling public officials to always check the status of the national funds. Local governments can also automatically send the results to the provincial government through the e-program. Therefore, the government can effectively manage the illegal execution of funds, such as embezzlement, bribery, poor execution, and fraudulent documents (Seo and Kim, 2016) [45]. Meanwhile, in Korea, Suwon City, Gyeonggi Province, adopted a new land investigation program using drones to secure accurate taxation data, shortening the investigation time, and manage public property.

Conducting audits using Big Data is also advantageous to auditors. PwC (2015) [48] reports that data analysts are changing the audit procedures with the new system. Auditors can use more information, including financial and non-financial data sets, and visualize the meaningful data. This study provided evidence from prior literatures that Big Data analytics can provide continuous audits and help mitigate audit risks (Vasarhelyi et al. (2010) [49]). Big Data will improve the quality and relevance of accounting information. This study also presented the case of Big Data combining Cloud computing together. For example, Smart A released by Douzone is an algorithm that applies Cloud and Big Data to allow users to proactively explore meaningful corporate information rather than just ex post facto exploration of financial information. In this way, Big Data is based on Cloud computing. We cannot store Big Data and meaningfully utilize them without the Cloud system.

WebCash, a Korean Accounting program provider based on Cloud technology, enables its client firms to make accounting, taxation, receipt management, payment, and remittance all at once. The Cloud server automatically records purchases and sales and collects detailed transaction data by the client so that outstanding or unpaid bills can be automatically managed. The customers of WebCash can handle large volumes of data without their own data center. At the same time, WebCash can make prompt responses possible so that their clients can manage key information of business in a more integrated manner. Bizplay was another example of the cases. It also provides the autonomous accounting processing app, and their clients can eliminate tedious and unproductive repetitive tasks for accounting records. The Bizplay app automatically matches each employee's corporate card usage records and generates quality reports with paperless receipts.

These cloud-based accounting innovations have brought changes to the management accounting aspect related to inventory management. One of the leading bakery companies in Korea, Orion, experienced a significant drop in product return rate. This was derived from the use of cloud-based Post of Sales (POS) data. Orion increased its sales through real-time identification of rapidly changing consumption trends. eBlueChannel was another Korean company that utilizes cloud-based POS data for inventory management. It is a data-based, integrated drug management solution that connects manufacturers, pharmacies, and wholesalers. In this medical care solution, pharmacies, hospitals, and pharmaceutical manufacturers are all connected. Hence, they can quickly identify drug and medicine inventory. It is a complete medical platform combining cloud services: therefore, they can manage their inventory in a more efficient way.

While Cloud computing makes it possible to store and utilize Big Data, it is revealed from the cases presented in this study that Big Data can be meaningfully used with AI technology. Big Data is an 
essential element of AI technology because AI can only function in deep learning or machine learning only with Big Data. Through the Korean cases that are building fraudulent accounting detection systems, it is emphasized that collecting financial fraud-related data is critical because the data can be an important source of AI using machine learning. The amount and quality of data are necessary to establish an automated accounting system applying machine learning and artificial intelligence techniques. The case of "Attack Board" was also discussed. It is a system provided by AGREEMENT, which is a Korean accounting software supplier. In "Attack Board," all employees and managers can access and visualize key performance index (KPI), setting up to achieve the business plan and goal. AGREEMENT developed a service that uses AI to predict future figures from historical data considered to impact or correlate with sales. "Attack Board" uses a variety of machine learning algorithms that can be handled by Python to make sales forecasts. It reveals that companies can develop a more accurate and efficient accounting system by combining Big Data and AI together.

Through Cloud computing, the valuable Big Data can be stored, and AI technology can effectively stylize these Big Data. Therefore, these technologies contribute to more advanced accounting information systems providing higher quality information with less time and costs and making it possible to achieve more transparent accounting. Here, the Blockchain technology will play a key role. Up to this point, it is examined how accounting technologies contribute to information generating or information managing activities. However, Blockchain contributes to information assuring activities. This study discussed the advantages of Blockchain technology. For example, it is difficult to manipulate transaction records because they are shared by all participants in the network. Blockchain verifies the validity of a transaction and secures the reliability of the data. uTradeHub and electronic trade infrastructure implemented by Korea Trade Network (KTNET) were provided as evidence of utilizing Blockchain in the accounting area. It is a single-window system in which exporters and importers can handle all trade affairs without interruption by linking a number of related agencies, such as commercial banks, customs service, shipping/air companies, ranging from marketing and credit rating to payment. It was established to simplify companies' trading procedures and enhance their trade operation efficiency. uTradeHub currently provides a unified workplace for trading companies to conveniently and instantly process all trade business, from marketing, commerce, foreign currency exchange, customs clearance, logistics, to payment without any interruption. It is expected to contribute towards trade automation innovation, and to bring the benefits of reducing trading-related costs, increasing efficiency, and preventing fraudulent transactions. Besides, KTNET is working to establish a service that automatically submits necessary electronic documents to the National Tax Service (Korean Customs Service, 2017) [57]. This is a service using Blockchain technology. Once in action, all transactions are identified and stored by each accounting subject using Blockchain technology. All transactions are recorded automatically with the unique number of the block in the ledger, and the transaction information and proof of accounting is stored together in the block. Therefore, it helps ensure transparency and reliability of the accounting information.

As mentioned above, these technologies are not separated from but rather intertwined with each other. The accounting process can be significantly improved by combining each element of new technologies (see Table 6).

Despite these advantages, it might be challenging to use them in real practice. The accounting technologies should be customized for each different organization. However, customizing it also requires time and efforts. For example, for continuous audit, both audited companies and auditors require a large-scale technical investment and company-wide training programs in order to build the audit system. Establishing legal system and regulation to force large investments for financial reporting is another obstacle. Currently, audit fees are set based on audit time, and they are expected to be significantly increased if continuous audit is actually employed. Total audit time may vary by increasing the preparation, operation, and time for the auditor's professional judgment, even though audit time for technical audit process would be shortened. There could be a discrepancy in interests between audited companies and auditors. 
Table 6. Accounting process possible with combining new technology.

\begin{tabular}{|c|c|c|c|c|}
\hline Accounting Process & Cloud & AI & Big Data & Blockchain \\
\hline Rapid processing & $\checkmark$ & & $\checkmark$ & $\checkmark$ \\
\hline Handle large volumes of data & $\checkmark$ & & & \\
\hline Accounting process automation & $\checkmark$ & $\checkmark$ & & $\checkmark$ \\
\hline Efficient inventory management & $\checkmark$ & & & \\
\hline Ensure accounting accuracy and efficiency & & $\checkmark$ & & \\
\hline Provide higher quality of accounting information & & $\checkmark$ & $\checkmark$ & $\checkmark$ \\
\hline Achieve accounting transparency & & $\checkmark$ & & $\checkmark$ \\
\hline Develop effective management control system & & & $\checkmark$ & \\
\hline Continuous audit & & $\checkmark$ & $\checkmark$ & \\
\hline Prevent manipulation & & & & $\checkmark$ \\
\hline Data integrity & $\checkmark$ & $\checkmark$ & $\checkmark$ & $\checkmark$ \\
\hline Simplify taxation process & & & & $\checkmark$ \\
\hline Control tax avoidance & & & & $\checkmark$ \\
\hline
\end{tabular}

Therefore, it is important to prepare appropriate guidelines for adopting these technologies into their own systems, which are suitable for each of their organizations to achieve breakthrough synergies in accounting systems. Analyzing the real-world examples and cases will help to provide ideas for the guidelines.

\section{Conclusions and Closing Remarks}

This study discusses the case of Korea introducing new technology into accounting. Some technologies are used to collect and produce accounting information and data. Some are used to provide quality information to make an efficient decision in practice, and some others are used to improve transparency and reliability of accounting quality. In some cases, private companies took the initiative in utilizing programs or software, and in some other cases, systems utilizing new technologies were used by local government. It is particularly interesting that in Korean markets, the government initiated a new infrastructure first leading to subsequent trend shifts from government-led to private-company-oriented.

As shown above, Korean companies have developed programs to process accounting information by combining Big Data technology and accounting AI in practice. For example, WebCash, a fintech start-up, utilizes a system that can automatically collect transaction data and generate the firm's financial statements. South Korean local governments adopt this automation system, so that they can extract various data needed for tax adjustment, automatically fill out key forms, and even automatically verify errors in tax report data. In addition, Douzone, the Korean firm providing accounting software, has been obtaining patents for accounting AI technology based on Big Data. The audit process is becoming transparent and timely, and audit on demand can be implemented. In Korean markets, the accounting technologies are actively used to read and extract massive number of complex documents related to major tasks in the organization, including mergers and acquisition, leases, and so on.

In the field of financial accounting and auditing, companies have already been developing and applying programs, such as Smart A, Gyeongninara, AGREEMENT and so on, that can understand corporate data through cognitive AI and Blockchain technology. These technologies help to organize and analyze accounting data to assist accountants, and achieve self-improvement through machine learning and deep learning.

The innovation of $\mathrm{AI}$ is changing the working environment. AI can be used for simple and repetitive tasks. Tasks with clear standards and conditions can also be completed using AI and Cloud system can support this. Blockchain offers increased information security and improves transparency in accounting. High-volume and time-consuming tasks, such as mailing, book-keeping, and data entry, have become almost possible with automation. 
Meanwhile, it has been revealed that it is not difficult to utilize AI and other technologies in managerial accounting area, which are already actively adopted in the field of financial accounting. Management accounting is not based on the mandatory accounting system, rather it should be developed based on the company's own situation. Management accounting is for optimal allocation of a company's capital or resources based on their own economic conditions or future forecasts. It is characterized by continuous change to find the optimal solution, therefore, the companies can identify the possibility through deep learnings and AI, and can produce the best solution without prior knowledge of the rules or specific accounting standards and systems (Marr, 2017) [58].

While the financial accounting and auditing analyze the data that has already occurred, management accounting has the characteristic of future orientation. Thus, predictive analysis using AI, Big Data, and Blockchain have become essential tools for management accounting to cope with rapid changes in global competitive environment and uncertainty. In the future, accountants and accounting experts need to study how the interface with the core technologies can be applied to strategic analysis and decision-making accounting in order to expand the accounting function. Up to these days, the availability of these technologies has been addressed and suggested in financial accounting and audit areas, and the attempt to adopt the technologies in management accounting is very limited, so research gaps exist. Therefore, finding an approach that can be applied to the management accounting area will also be a meaningful topic for future research.

However, irregular real-life activities, requiring social intelligence, such as negotiation, persuasion, care, creative intelligent, producing ideas, understanding, and interacting with complex patterns are difficult to replace by AI. Therefore, we need to understand that these technologies are not tools to replace experts, but ones that improve estimation and predictions. It should also be understood that estimations are just one of the several opinions about the decision-making process. Agrawal et al. (2018) [59] argued that forecasts promote judgement by reducing uncertainty and that judgments provide value. ML can accelerate the process of forecasting by sorting and finding patterns, but it is difficult for machines to evaluate and decide something. This is the domain of human expertise. Accounting is an information system that provides useful information for decision-making. These technologies simply enhance this accounting system. Therefore, we must keep in mind that providing useful information can be replaced by the technologies, but implementing decision-making is only up to human beings. Human accounting experts must make the final decisions. Gerald Stokes, a professor at the State University of New York in Korea, said it was disastrous for machines to take over the responsibilities of humans. Even if AI had self-thinking skills, the final judgment is always up to human beings (Stokes, 2020) [60].

The accounting technologies introduced in this study have now become basic trends that cannot be delayed or avoided. This transformation is expected to be accelerated, especially after COVID-19. Without understanding and adopting these technologies, we cannot survive in a fast-changing business environment. Therefore, it is necessary to understand, think about how to apply them, and develop creative fields that such technologies can be applied to. Further, while new technologies offer many opportunities, there are also several associated risks, such as errors, server-down, data backup, and so on. This study offers guidelines for the application of technologies to actual accounting practices, also contributing to the development of areas that can be utilized, the capabilities of future human experts to live with new technologies, and providing opportunities to contemplate related risks and threats.

This study is meaningful because it provides examples showing the adoption of these technologies in actual practice, allowing us to explore ways to effectively utilize and manage them. This study also initiates the process of organizations finding ways to properly adopt new technologies. It is also time to think about the capabilities human accountants need.

Despite the contributions, this study has some limitations. There are many other types of accounting technologies. However, this study presents only a few of them. The purpose was to 
introduce some examples from Korea. Hence, there were limitations in providing more detailed descriptions for each one of them. Future research must address the same.

Funding: This research received no external funding.

Conflicts of Interest: The authors declare no conflict of interest.

\section{References}

1. Frey, C.; Osborne, M. The future of employment: How susceptible are jobs to computerization? Technol. Forecast Soc. Chang. 2017, 114, 254-280. [CrossRef]

2. PwC. Global Industry 4.0 Survey. 2016. Available online: http://www.pwc.com/gx/en/industries/industry-4.0. html (accessed on 24 September 2020).

3. Piccarozzi, M.; Aquilani, B.; Gatti, C. Industry 4.0 in management studies: A systematic literature review. Sustainability 2018, 10, 3821. [CrossRef]

4. Milian, E.Z.; Spinola, M.D.M.; De Carvalho, M.M. Fintechs: A literature review and research agenda. Electron. Commer. Res. Appl. 2019, 34, 100833. [CrossRef]

5. Arundel, A.; Bloch, C.; Ferguson, B. Advancing innovation in the public sector: Aligning innovation measurement with policy goals. Res. Policy 2019, 48, 789-798. [CrossRef]

6. Rikhardsson, P.; Yigitbasioglu, O. Business intelligence \& analytics in management accounting research: Status and future focus. Int. J. Account. Inf. Syst. 2018, 29, 37-58. [CrossRef]

7. ACCA/IMA. Digital Darwinism: Thriving in the Face of Technology Change. Available online: https://www.accaglobal.com/in/en/technical-activities/technical-resources-search/2013/october/ digital-darwinism.html (accessed on 28 July 2020).

8. IFAC. Technology and the Profession-A Guide to ICAEW's Work. 2019. Available online: https://www.ifac.org/knowledge-gateway/preparing-future-ready-professionals/discussion/technologyand-profession-guide (accessed on 20 May 2020).

9. Chandi, N. Accounting trends of tomorrow: What you need to know. Forbes 2018, 13A.

10. Ionescu, B.; Ionescu, I.; Bendovschi, A.; Tudoran, L. Traditional accounting vs. cloud accounting. In Proceedings of the 8th International Conference Accounting and Management Informational Systems, Bucharest, Romania, 12-13 June 2013; pp. 106-125.

11. Christauskas, C.; Misevicience, R. Cloud computing based accounting for small to medium sized business. Inz. Ekon. Eng. Econ. 2012, 23, 14-21. [CrossRef]

12. Phillips, B.A. How Cloud Computing Will Change Accounting Forever. 2012. Available online: https:// docplayer.net/2537016-How-the-cloud-will-change-accounting-forever.html (accessed on 16 February 2020).

13. FSB (Financial Stability Board) Artificial Intelligence and Machine Learning in Financial Services: Market Developments and Financial Stability Implications. 2017. Available online: http://www.fsb.org/wp-content/ uploads/P011117.pdf (accessed on 25 July 2020).

14. Deloitte. The New Machinery of Government: Robotic Process Automation in the Public Sector. 2017. Available online: http://www2.deloitte.com/content/dam/Deloitte/uk/Documents/Innovation/deloitte-ukinnovation-the-new-machinery-of-govt.pdf (accessed on 18 December 2019).

15. Ahn, S.; Jung, H.R. A study on the role of public officials in local governmental accounting. Korean Gov. Account. Rev. 2018, 16, 67-91. [CrossRef]

16. Bauguess, $\mathrm{S}$. The role of big data, machine learning, and $\mathrm{AI}$ in assessing risks: A regulatory perspective. In Champagne Keynote Speech; Securities and Exchange Commission: New York, NY, USA, 2017. Available online: https://www.sec.gov/news/speech/bauguess-big-data-ai (accessed on 21 June 2020).

17. Cho, J.S.; Ahn, S.; Jung, W. The impact of artificial intelligence on the audit market. Korean Account. J. 2018, 27, 289-330. [CrossRef]

18. Warren, J.D.; Moffitt, K.; Byrnes, P. How Big Data will change accounting. Account. Horiz. 2015, 29, 397-407. [CrossRef]

19. IAASB. Data Analytics Working Group: Exploring the Growing Use of Technology in the Audit; With a Focus on Data Analytics. 2016. Available online: https://www.ifac.org/system/files/publications/files/IAASBData-Analytics-WG-Publication-Aug-25-2016-for-comms-9.1.16.pdf (accessed on 12 July 2020). 
20. Raval, S. What Is a Decentralized Application? Harnessing Bitcoin's Blockchain Technology, O'Reilly Media Inc.: Sebastopol, CA, USA, 2016.

21. Iansiti, M.; Lakhani, K.R. The truth about Blockchain. Harvard Bus. Rev. 2017, 95, 118-127.

22. PwC. Q\&A: What's Next for Blockchain in 2016? 2016. Available online: www.pwc.com/us/en/financialservices/publications/viewpoints/assets/pwc-qa-whats-next-for-blockchain.pdf (accessed on 20 April 2020).

23. Schmitz, J.; Leoni, G. Accounting and auditing at the time of blockchain technology: A research agenda. Aust. Account. Rev. 2019, 29, 331-342. [CrossRef]

24. Cockcroft, S.; Russell, M. Big data opportunities for accounting and finance practice and research. Aust. Account. Rev. 2018, 28, 323-333. [CrossRef]

25. Feng, J. Cloud accounting: The transition of accounting information model in the big data background. In Proceedings of the 2015 International Conference on Intelligent Transportation, Big Data \& Smart City, Halong Bay, Vietnam, 19-20 December 2015; pp. 207-211.

26. Kim, A. Cloud ERP. Financ. News 2020, 7, 5-6.

27. Kim, G. Webcash boom due to the popularity of Gyeongninara. Maeil Bus. News Korea 2020, 5, 17-18.

28. Lee, S. Trend: Automatic accounting for corporate credit card. Maeil Bus. News Korea 2020, 7, 8.

29. Lee, H. Inventory management: The case of Orion. Maeil Bus. News Korea 2020, 7, S5-S6.

30. Sularto, L.; Wardoyo, L.; Yunitasari, T. User requirements analysis for restaurant POS and accounting application using quality function deployment. Procedia Soc. Behav. Sci. 2015, 169, 266-280. [CrossRef]

31. eBlueChannel. 2020. Available online: https://www.eblu.co.kr/en/bluechannel/ (accessed on 2 February 2020).

32. Yook, K.H. Challenges and prospect for management accounting in Industry 4.0. Korean J. Manag. Accoun. Res. 2019, 19, 33-57.

33. Shin, K. Artificial Intelligence Applications in Fraudulent Accounting Detection. In Proceedings of the Conference of Research on the Future Accounting, Korean Accounting Association, Seoul, Korea, 8 December 2017.

34. Breiman, L. Random forests. Mach. Learn. 2001, 45, 5-32. [CrossRef]

35. Cutler, A.; Cutler, D.R.; Stevens, J. Random forests. In Ensemble Machine Learnings; Springer: Manhattan, NY, USA, 2012; pp. 157-175.

36. Deloitte. AI-Augmented Government: Using Cognitive Technologies to Redesign Public Sector Work. 2017. Available online: https://www2.deloitte.com/content/dam/insights/us/articles/3832_AI-augmentedgovernment/DUP_AI-augmented-government.pdf (accessed on 18 December 2019).

37. Schatsky, D.; Muraskin, G.; Iyengar, K. Robotic Process Automation: A Path to the Cognitive Enterprise. Deloitte University Press. 2016. Available online: https://www2.deloitte.com/content/dam/Deloitte/nl/ Documents/financial-services/deloitte-nl-fsi-roboticsbrochure-abnamro.pdf (accessed on 14 September 2019).

38. O'Neill, E. How is the Accountancy and Finance World Using Artificial Intelligence? Acctech Institute. 2016. Available online: http://www.acctechinstitute.com/how-is-the-accountancy-and-finance-world-usingartificial-intelligence (accessed on 31 July 2020).

39. Kira. Kira for Contract Analysis. 2018. Available online: https://kirasystems.com/how-it-works/contractanalysis/ (accessed on 15 April 2020).

40. PwC. Spotlight: Robotic Process Automation (RPA), What Tax Needs to Know Now. PwC Tax Function of the Future Series: A Focus on Today. 2017. Available online: https://www.pwc.com/gx/en/tax/publications/assets/ pwc-tax-function-of-the-future-focus-on-today-robotics-process-automation.pdf (accessed on 3 May 2020).

41. Song, W. Blocking Smart Tax Evasion with Big Data, SBS News. 2017. Available online: https://news.sbs.co. kr/news/endPage.do?news_id=N1004496340\&plink=COPYPASTE\&cooper=SBSNEWSEND (accessed on 22 November 2019).

42. Korean National Tax Service. Support for sincere tax payment and setting compliance tax. In Proceedings of the 2016 Joint Meeting of the National Tax Administration Reform Committee, Daejeon, Korea, 16 November 2016.

43. Lee, S.; Kim, I.; Kwon, S.; Yoon, I.; Cho, H. A Study on the Data Analysis Management System for Local Government Policy Support; Daegu University: Daegu, Korea, 2015.

44. Kwon, O.; Lee, J.; Kim, Y. A study on the Big Data in financial accounting information. KIPA Res. Rep. 2014, 27, 1-321.

45. Seo, J.; Kim, S. Effective management of local government aids. In Research Report; Korea Institute of Local Administration: Daejeon, Korea, 2016; pp. 1-150. 
46. Kim, A. Managing land by flying drones. Financ. News 2018, 7, 4.

47. Kim, I. Drones investigate illegal change of land. Suwon Yonhap News 2018, 7, 9.

48. PwC. What Students Need to Succeed in a Rapidly Changing Business World? 2015. Available online: https://www.pwc.com/us/en/faculty-resource (accessed on 20 April 2020).

49. Vasarhelyi, M.; Alles, M.; Teeter, R. Remote audit. J. Emerg. Tech. Account. 2010, 7, 73-88.

50. Hoogduin, L.; Yoon, K.; Zhang, L. Integrating different forms of data for audit evidence: Markets research becoming relevant to assurance. Account. Horiz. 2014, 29, 431-438.

51. Nakamoto, S. Bitcoin: A Peer-to-Peer Electronic Cash System. 2008. Available online: http://bitcoin.org/ bitcoin.pdf (accessed on 20 May 2020).

52. Hughes, L.; Dwivedi, Y.K.; Misra, S.K.; Rana, N.P.; Raghavan, V.; Akella, V. Blockchain research, practice and policy: Applications, benefits, limitations, emerging research themes and research agenda. Int. J. Inf. Manag. 2019, 49, 114-129. [CrossRef]

53. Fanning, K.; Centers, D.P. Blockchain and its coming impact on financial services. J. Corp. Account. Financ. 2016, 27, 53-57. [CrossRef]

54. Kim, G.Y. No question, without question, set aside 40 billion dollars? Block Media 2018, 8, 2.

55. Lee, H.; Yoon, N.; Park, S.; Lee, C.; Hwang, S. A study on the accounting information system based on Blockchain. Korean Account. J. 2019, 28, 273-300. [CrossRef]

56. Hong, S. Digital ID utilizing Blockchain technology. Maeil Bus. News Korea 2020, 5, 3-4.

57. Korean Customs Service. Technical Verification of the World's First Blockchain-Based Export Customs Clearance Service; The Korean Customs Service Press: Daejeon, Korea, 2017.

58. Marr, B. Data Strategy: How to Profit from a World of Big Data, Analytics and the Internet of Things; Kogan Page: London, UK, 2017.

59. Agrawal, A.; Gans, J.; Goldfarb, A. Prediction Machines: The Simple Economics of Artificial Intelligence; Harvard Business Review Press: Brighton, MA, USA, 2018; ISBN 978-1-633695672.

60. Stokes, G. Biz Focus: It's still up to us to make our own final decision. Maeil Bus. News Korea 2020, 7, S3.

Publisher's Note: MDPI stays neutral with regard to jurisdictional claims in published maps and institutional affiliations.

(C) 2020 by the author. Licensee MDPI, Basel, Switzerland. This article is an open access article distributed under the terms and conditions of the Creative Commons Attribution (CC BY) license (http://creativecommons.org/licenses/by/4.0/). 